\title{
Educação Sexual: ética, liberdade e autonomia
}

\section{Sexual education: ethics, freedom and autonomy}

\author{
Helena Altmann* \\ Carlos José Martins**
}

\begin{abstract}
RESUMO
O objetivo desse artigo é refletir sobre o tema da educação sexual à luz dos conceitos de ética, liberdade e autonomia. Na perspectiva aqui adotada, não se trata de definir a priori conceitos que nos dariam uma grade de categorias que pudessem estabelecer o que é ético e o que não é ético. Tão somente, não se trata de estabelecer um critério distintivo do que seja moral e, por conseguinte, prescritivo e normativo, do que é princípio ético, objeto de livre escolha dos indivíduos e, portanto, emblema de sua autonomia. Trata-se de remeter os problemas éticos à dinâmica imanente das práticas sociais. Considerando a ética como uma prática refletida da liberdade, trata-se de exercitar tal prática, encorajando os/as atores/as a debater em torno das decisões e escolhas a serem feitas. Deste modo, esse artigo se volta para as seguintes questões: De que forma poderia a sexualidade ser trabalhada na escola a partir de uma ética como prática da liberdade e não de uma moral prescritiva? Como poderia um trabalho de educação sexual produzir reflexão e autonomia? Tais questões serão abordadas a partir da análise de uma atividade de educação sexual, sobre o tema da paternidade, desenvolvida em uma escola.
\end{abstract}

Palavras-chave: educação sexual; ética; escola; sexualidade; gênero.

* Doutora em Educação pela PUC-Rio. Professora na UNICAMP, altmann@fef.unicamp. br

** Doutor em Filosofia pela UFRJ. Professor na UNESP - Rio Claro, carlosjmartins@ hotmail.com 


\begin{abstract}
This paper deals with the topic of sexual education as it relates to the concepts of ethics, freedom and autonomy. The approach presented here does not consider any a priori concepts defining what is ethic and what is not, neither proposes a distinctive criterion about what is moral. As a consequence, it is not prescriptive or normative in relation to the ethical principal of freedom. The idea is to direct ethical problems to the dynamics embedded in social practices. Considering ethics as a practice of freedom, it intends to exercise this practice, encouraging actors to debate about the decisions and choices to be made. This paper is focused on the following questions: In which way could issues of sexuality be treated in schools as a practice of freedom and not from a prescriptive moral? How could sexual education produce reflections and autonomy? These questions are addressed based on the analysis of a sexual education activity developed in a school related to paternity.
\end{abstract}

Keywords: sexual education; ethics; school; sexuality; gender.

A educação sexual se faz presente em escolas, parâmetros e propostas curriculares, cursos de educação à distância, programas sociais, políticas públicas, matérias de jornais e programas de televisão voltados a jovens, entre outros $^{1}$. Sob diferentes enfoques, a sexualidade é tematizada e transformada em foco de intervenção. Uma verdadeira proliferação discursiva sobre a sexualidade atravessa o campo educacional. Neste sentido, ela dá prosseguimento a um fenômeno histórico descrito, com grande precisão, por Michel Foucault. Segundo o filósofo francês:

[...] seria inexato dizer que a instituição pedagógica impôs um silêncio geral ao sexo das crianças e dos adolescentes. Pelo contrário, desde o século XVIII ela concentrou as formas do discurso neste tema; estabeleceu pontos de implantação diferentes; codificou os conteúdos e qualificou os locutores. Falar do sexo das crianças, fazer com que dele falem os educadores, os médicos, os administradores e os pais; ou, então, falar de sexo com as crianças, fazer falarem elas mesmas, encerrá-las numa teia de discursos que ora se dirigem a elas, ora falam delas, impondolhes conhecimentos canônicos ou formando, a partir delas, um saber que lhes escapa - tudo isso permite vincular a intensificação dos controles à

1 De acordo com Maria Rita César (2008) a educação sexual nas escolas brasileiras não é uma particularidade das últimas décadas, ao contrário constitui uma preocupação que remonta as primeiras décadas do século passado. Sobre a educação sexual escolar, vide também Altmann (2005). 
multiplicação dos discursos. A partir do século XVIII, o sexo das crianças e dos adolescentes passou a ser um importante foco em torno do qual se construíram inúmeros dispositivos institucionais e estratégias discursivas (FOUCAULT, 1997, p. 31).

Assim, em nossa sociedade, fala-se publicamente do sexo "como de uma coisa que não se deve simplesmente condenar ou tolerar, mas gerir, inserir em sistemas de utilidade, regular para o bem de todos, fazer funcionar segundo um padrão ótimo. O sexo não se julga apenas, administra-se" (FOUCAULT, 1997, p. 27). Por conseguinte, o sexo é, de um lado, objeto de tecnologias de governo afeitas ao campo político e, de outro, objeto de escolhas afeitas ao campo ético. Portanto, constitui-se como um dispositivo complexo de técnicas de governo de si e dos outros. Daí a importância de colocar em discussão o tema de uma educação sexual à luz dos conceitos de ética, liberdade e autonomia. Conceitos eminentemente pertinentes ao escopo da ética e da política.

Colocado nestes termos, um campo de problemas se abre às nossas práticas educacionais. De que modo, portanto, pensar em uma ética da educação sexual considerada a partir de suas relações com a liberdade e a autonomia? Como ultrapassar o moralismo e a normalização? Como intervir sem ser prescritivo? Tais são alguns dos desafios sobre os quais esse artigo se propõe a refletir.

\section{Ética como prática refletida da liberdade}

O debate corrente acerca do tema da ética consiste em estabelecer semelhanças e distinções entre ética e moral. Etimologicamente ética vem do grego ethos e moral vem do latim mores ambas significando costume. Em outros termos, ética e moral remetem ao conjunto de costumes de uma sociedade considerados valores e regras para a conduta de seus membros. Sócrates, por exemplo, interrogava o que eram, de onde vinham e o que valiam tais costumes (CHAUÍ, 1995).

Contudo, por ser passível de tais indagações em razão de sua natureza social e culturalmente contingente, não há consenso absoluto quanto ao sentido dessas palavras. Existem diversas maneiras de distinguir seus significados de acordo com o campo de práticas onde são empregados. Um modo de diferenciar consiste em chamar de moral os valores e regras de uma sociedade e de ética, valores e regras de uma determinada corporação. Por exemplo, a ética médica, os 
códigos de ética que regem a pesquisa científica etc. Nessa perspectiva, pode-se perguntar sobre a ética do professor que trabalha com educação sexual na escola: quais seriam os princípios éticos que deveriam reger seu trabalho?

Outra diferenciação clássica consiste em reservar o nome de ética à filosofia da moral ou à ciência da moral. A moral seria o objeto (valores e condutas dos indivíduos) e a ética seria a ciência que refletiria sobre esse objeto, sobre sua definição, sua origem, sobre os critérios que definem o que é certo e errado etc.

De acordo com uma terceira forma de diferenciar ética de moral, a moral seriam regras precisas de conduta, enquanto a ética, os princípios norteadores que regem as condutas. A ética seria o conjunto de princípios que dão rumo ao pensar sem, de antemão, prescrever formas de conduta ou regras precisas e fechadas de comportamento. "Não matar", "não roubar", "não mentir", "ser fiel" são exemplos que correspondem à moral, pois dizem claramente o que se deve ou não fazer. Em compensação, a expressão "amai-vos uns aos outros" responderia a um princípio ético, uma vez que se trata de uma orientação geral da conduta cuja tradução em regras precisas deve ser criada pelos indivíduos.

Em nosso trabalho procuramos indagar quanto à possibilidade de pensar a ética enquanto uma pratica da liberdade e da autonomia. Por conseguinte, não partimos de parâmetros previamente colocados seja pelas regras rígidas de uma moral ou pelos princípios transcendentes de uma ética. Partimos dos problemas éticos e morais engendrados pelo campo específico das práticas colocadas em questão. Aqui, em particular, as práticas do campo da educação sexual.

Notadamente, a sexualidade está permeada de preceitos éticos e morais que regem as nossas condutas. Alguns deles, restritivos, outros, imperativos. Alguns nos dizem o que não devemos fazer e outros, o que devemos. Também dentro das escolas, os preceitos morais que regem a sexualidade são muitos e, não raro, norteiam trabalhos de educação sexual.

No entanto, se a sexualidade fosse regida por preceitos rígidos, não caberia perguntar sobre o espaço para a liberdade e a autonomia. Se a questão dos direitos sexuais e reprodutivos apenas se colocasse como uma questão de garantia e obediência a direitos adquiridos, o sujeito que segue a essas normas não teria autonomia para tomar decisões, não precisaria refletir sobre uma situação, pois normas morais e direitos definiriam plenamente a sua conduta. Isso, porém, não esgota os problemas colocados pelo campo ético. Enquanto o hábito e a heteronomia podem bastar a uma determinada concepção de moral, a ética como prática da liberdade exigiria reflexão e autonomia ${ }^{2}$.

Ao refletir sobre as possibilidades de se definir uma ética para a sexuali-

2 Heteronomia aqui é entendida como sujeição a uma lei exterior ou a vontade de outrem, enquanto autonomia, capacidade de se autogovernar. 
dade humana, Yves de La Taille (1998) argumenta acreditar que o princípio do respeito mútuo seria suficiente. Deste princípio, uma série de outros decorreriam, como o da não violência, do cuidado com o próprio corpo e do parceiro, do cuidado com o prazer, da igualdade de condições a homens e mulheres, da responsabilidade perante um/a possível filho/a, entre outros.

Consideramos que o princípio do respeito mútuo possa ser desejável. No entanto, dada a complexidade dos problemas que atravessam o campo da educação sexual, não nos parece suficiente. Em tais concepções subjaz a premissa do consenso ou de um princípio transcendente aceito a priori pelas partes envolvidas. Todavia, nem sempre se pode contar previamente com tais condições.

Neste sentido, de que forma poderia a sexualidade ser trabalhada na escola a partir de uma ética como prática da liberdade e não de uma moral prescritiva? Como poderia um trabalho de educação sexual produzir reflexão e autonomia? Tais questões exigem outra forma de compreender o conceito de ética. Pensar a ética como prática de liberdade e autonomia é o que nos propomos a seguir. Para tanto, faremos isso recorrendo ao exemplo histórico da instituição do divórcio no Brasil, mostrando os embates políticos e lutas sociais em torno dessa questão. $\mathrm{O}$ objetivo aqui é analisar como mudanças sociais em torno das relações afetivas, conjugais e em relação aos/as filhos/as dizem respeito a questões éticas que também remetem à educação sexual. Tais questões serão retomadas posteriormente a partir da análise de uma atividade desenvolvida em uma escola.

Apesar do debate político sobre a instituição ou não do divórcio no Brasil poder ser vislumbrada desde a Constituinte de 1891 (ARCHANJO, 2006), o primeiro divórcio no Brasil foi efetivado apenas em 1977. Antes disso legalmente só era permitido o desquite, em que havia a quebra do vínculo conjugal, com separação do casal e de seus bens, mas sem a quebra do vínculo matrimonial. Uma pessoa desquitada não poderia contrair um novo casamento. $\mathrm{O}$ casamento era visto como uma instituição e não como um contrato civil, ou seja, uma vez contraído, tornava-se indissolúvel. A revisão dos conceitos de família, casamento e suas relações deve-se, em muito, aos diferentes modelos sociais de luta por liberdade e igualdade, que ganharam força na década de 1960. Todavia, a forte resistência encontrada pelos divorcistas aponta para o vigor da ordem instaurada, representada, sobretudo, pela reafirmação do discurso católico e pela ideologia patriarcal que o norteia. Tal processo é analisado por Daniela Archanjo, ao mostrar que, a introdução do divórcio na legislação brasileira atingia três pontos importantes da organização da sociedade: o jurídico, o religioso e o social (ARCHANJO, 2008). A família era vista como uma instituição fundamental à sociedade e a existência social da mulher estava condicionada à maternidade. Ao analisar os discursos dos parlamentares em torno da legalização do divórcio, Archanjo demonstra o caráter conservador dos discursos antidivorcista e 
divorcista. A família que ambos queriam preservar era a mesma: enquanto os antidivorcistas defendiam a unicidade do casamento, os divorcistas defendiam a possibilidade do re-casamento. Temendo o destino da mulher desquitada que, sem um homem que a amparasse e chefiasse a sua vida, corria o risco de perder a "dignidade" e a "pureza", os divorcistas afirmavam que o divórcio permitiria a legalização de uma nova família e, ao amparar a mulher, a livraria muitas vezes de rolar pelo abismo da prostituição (ARCHANJO, 2006). Afirma a autora: "Chama a atenção a estrutura conservadora do discurso divorcista, já que, no plano social, a luta pela dissolubilidade do casamento poderia apontar para a re-significação da família e para a reformulação do papel social da mulher".

Percebe-se aí que a atual aceitação do divórcio por grande parte da sociedade brasileira não ocorreu numa sucessão abstrata de valores e condutas no leito plácido do curso do tempo. Tais mudanças dão-se a partir de problemas engendrados no interior dos campos social, jurídico, político e religioso. Por conseguinte, mais importante que as leis em si é a jurisprudência, pois é através desta que as leis mudam e são criadas tendo em vista os problemas éticos e políticos oriundos das disputas sociais e culturais. Não obstante o aspecto legal é preciso ressaltar que o campo dos problemas éticos não se reduz ao plano jurídico e/ou normativo. Notadamente, não se esgota o campo ético no plano dos direitos adquiridos. As questões éticas se colocam de forma contundente quando remetidas a um campo problemático no qual escolhas individuais e coletivas colocam-se em jogo a partir de conflitos e disputas concretas. Tal campo estrutura-se entre a instância codificada da regra e o modo pelo qual os indivíduos se constituem como sujeito ético em relação ao código de regras. Dado um código de ação no interior de um campo de ações determinado, que se define pelo grau de adesão ou divergência com relação a tal código, diferentes maneiras de se conduzir são possíveis para o indivíduo que age. Neste sentido, a ética encontra-se remetida à problemática do governo das condutas. Configurando-se assim um campo intrinsecamente ético-político de problemas, qual seja como governar a si mesmo e aos outros. Como conduzir-se e como conduzir condutas de outrem de forma ética? Portanto, se a educação é uma arte de conduzir condutas, como educar para a autonomia e para a liberdade? Tal é o caso do campo dos problemas colocados em torno da educação sexual que aqui serão analisados.

Deste modo, entendemos equacionar os problemas éticos em outros termos. Não se trata apenas de definir a priori conceitos que nos dariam uma grade de categorias que pudessem estabelecer o que é ético e o que não é ético. Tão somente não se trata de estabelecer um critério distintivo do que seja moral e, por conseguinte, prescritivo e normativo, logo, fruto de heteronomia, do que é princípio ético objeto de livre escolha dos indivíduos e, portanto, emblema de 
sua autonomia. Trata-se de remeter os problemas éticos à dinâmica imanente das práticas sociais. De outro modo, tais problemas arriscariam redundar em querelas conceituais especulativas.

O mesmo tratamento vale para os conceitos de autonomia e liberdade. Nestes casos, não se trata de conceitos estanques. Antes pelo contrário, procuraremos demonstrar como estes conceitos articulam-se entre si. No escopo aqui adotado, a liberdade é tomada como condição ontológica da ética. E a ética é a forma refletida assumida pela liberdade (FOUCAULT, 1994). Logo, é necessário que os atores implicados não estejam submetidos a uma coerção ou obediência absolutas, mas que exista margem de escolha e manobra a suas condutas, por mais problemáticas que sejam. A instauração de um campo ético se dá a partir da emergência de um campo problemático. Tal campo se estrutura através das questões colocadas pelos próprios atores envolvidos no contexto específico das práticas sociais. Deste modo, a autonomia vincula-se à ética através da questão do autogoverno individual e coletivo cujas articulações dar-se-ão em torno dos problemas que estiverem em pauta.

Neste enfoque, portanto, a premissa é outra. Se a ética é uma prática refletida da liberdade, logo, trata-se de exercitar tal prática em relação às questões suscitadas pelo campo. Em nosso caso, em torno dos temas da sexualidade, encorajando os/as atores/as a debater acerca das decisões e escolhas a serem feitas. Não há definição prévia que possa eximir ou poupar o sujeito das eventuais angustias inerentes aos dilemas das escolhas. Parece-nos mais inadequadas as atitudes e condutas que, em nome da proteção do/a "menor", procuram tutelar suas escolhas diminuindo assim sua potência de agir. Tal perspectiva será abordada na análise de uma atividade desenvolvida em uma escola.

\section{Paternidade em debate}

No ano de 2002, o então prefeito da cidade do Rio de Janeiro, César Maia, instituiu, por decreto, a segunda semana de agosto como a "Semana de Valorização da Paternidade". Tal medida foi justificada pela identificação de que "o envolvimento do homem no cuidado com crianças e adolescentes é fundamental para o desenvolvimento saudável, a prevenção da violência e a responsabilidade masculina no planejamento familiar" e pela "necessidade de ampliar a reflexão sobre o significado da paternidade na sociedade atual" (RIO DE JANEIRO, 2002). De acordo com o artigo segundo deste decreto, durante essa semana, 
[...] escolas, unidades de saúde, Centro Municipal de Atendimento Social Integrado, abrigos, centros esportivos e culturais, bibliotecas e demais equipamentos e projetos municipais, que trabalhem com crianças, adolescentes e suas famílias, devem desenvolver atividades voltadas para o tema da paternidade e do envolvimento dos homens no cuidado com crianças e adolescentes (RIO DE JANEIRO, 2002).

No ano de 2002, as atividades referidas no artigo acima deveriam desenvolver o tema "O que é ser pai?".

Atendendo a essa determinação legal, a Secretaria Municipal de Educação desse município, propôs as seguintes atividades para estudantes de $5 .{ }^{\mathrm{a}}$ a 8 . ${ }^{\mathrm{a}}$ séries. Intitulada "Um recado para você: você vai ser pai!", a dinâmica tinha como objetivo "explorar a decisão sobre o ato de assumir a paternidade: suas implicações afetivas e sociais". Para a dinâmica, sugeria-se a formação de três grupos, sendo que cada um receberia um bilhete com uma situação que deveria ser interpretada pelo grupo. As situações eram as seguintes:

(1) casal com relacionamento duradouro, cuja gravidez acontece sem planejamento;

(2) pessoas que se encontram apenas uma noite, que possuem amigos em comum e cuja gravidez não era esperada;

(3) casal que deseja ter um filho e que recebe um resultado positivo no laboratório (AMBIENTE EM REDE, 2002, p. 3).

O informativo também sugeria as seguintes perguntas para a discussão:

- Se o rapaz assumir a paternidade, o que vai precisar fazer?

- Se o rapaz não assumir a paternidade, o que a moça pode fazer?

- O que é assumir a paternidade?

- Eles devem casar?

- Como se sente o homem quando recebe a notícia de que sua parceira está grávida?

- Como os jovens percebem a mulher que tem relações sexuais com um homem, no primeiro encontro?

- Qual a idade de cada um dos casais?

- Existe diferença entre a gravidez que acontece numa relação duradoura e uma gravidez que acontece numa transa eventual?

- Se a mulher quisesse interromper a gravidez e você quisesse ter o filho, 
o que você faria?

- E se você quisesse interromper a gravidez e a mulher quisesse ter o filho, o que você faria?

(AMBIENTE EM REDE, 2002, p. 3).

Tal dinâmica foi colocada em prática em uma escola municipal do Rio de Janeiro, tendo como resultado um intenso debate entre os/as estudantes (ALTMANN, 2005, 2009). Três experiências diferentes de gravidez em relacionamentos com características distintas alavancaram o debate. Neste artigo propomo-nos a problematizar eticamente a dinâmica adotada e dois pontos que emergiram no debate.

Ao longo da discussão, havia certa concordância de que um casal não deveria necessariamente casar como consequência de uma gravidez. No máximo, se quisessem e gostassem um do outro, deveriam morar juntos e avaliar se a relação teria ou não continuidade. Essa decisão mostra uma mudança significativa em relação a como lidar com uma gravidez entre um casal de namorados ou de "ficantes" - para utilizar uma expressão jovem contemporânea. Para muitos, a necessidade de casar como decorrência de uma gravidez não é mais vista como uma obrigação. Vemos aí, um sinal de mudança nos parâmetros éticos de uma determinada forma de sociabilidade. Em diferentes momentos históricos, observamos costumes e normas distintas regendo os comportamentos. Em outros tempos, o imperativo do casamento estava colocado em uma situação como essa, quando a gravidez fora de um casamento era inaceitável, e não tolerável como o é hoje. O casamento era uma forma de "salvar a reputação" da moça e "manter a honra" do rapaz. Podemos dizer que casar era um imperativo do código moral à época. Hoje em dia, há uma maior margem de liberdade de escolha que regula a relação com as normas de conduta em relação à gravidez e aos relacionamentos. As mudanças sociais em relação à época da institucionalização do divórcio no Brasil são evidentes. Se, no final da década de 1970, a família era vista como uma instituição fundamental à sociedade, sendo o casamento indispensável, o debate aqui suscitado demonstra uma flexibilização dessa norma.

Em relação ao segundo ponto, referente à responsabilidade pela gravidez, o debate explicitou uma concepção de que, apesar da responsabilidade pela prevenção da gravidez ser, a princípio de ambos, a responsabilidade da menina seria maior. Por serem elas que engravidam, o assunto gravidez acaba sendo considerado de maior interesse e responsabilidade das mulheres. Conforme manifestaram também durante as entrevistas, a menina é tida como mais responsável pela gravidez do que o menino, "porque é no corpo dela, ela que vai ficar grávida" (Laura, 14 anos). A esse respeito, Felipe (14 anos) afirmou: "Eu acho 
que pode ser os dois: o garoto para não pegar doença e a garota para não pegar doença e não ter filho". Outra menina disse: "Eu acho que a responsabilidade da gravidez é dos dois. Eu não quis ter o filho sozinha, eu não ia querer ter o filho sozinha. Mas eu acho que é mais irresponsabilidade dela, sabendo que ela podia usar camisinha" (Júlia, 14 anos). Mesmo naquelas falas em que uma parcela de responsabilidade era atribuída ao menino, ela era menor do que a da menina: a responsabilidade é de ambos, mas a irresponsabilidade é da menina; ele deve usar um preservativo para não pegar doenças, ela, também, para não engravidar (ALTMANN, 2005).

O impacto da gravidez também era visto como sendo maior na vida da menina do que na do menino. Quando falavam sobre o que muda na vida de um garoto quando ele se torna pai, mencionaram que terá de trabalhar para sustentar a criança e que deve ajudar a garota - sendo companheiro, conversando, compreendendo-a. Para aqueles estudantes, a responsabilidade do menino com o/a filho/a é apenas financeira, nunca mencionaram alguma necessidade em termos de cuidados em criar o bebê. Para a menina, a maternidade "muda tudo", faz com que ela "perca a sua juventude", pois seu corpo muda, ela sente as dores do parto, tem de cuidar do bebê, não pode sair, precisa ser mais responsável, tem de deixar de estudar por algum tempo, entre outros ${ }^{3}$.

Assim, a criação de uma semana de valorização da paternidade por iniciativa do poder público municipal está fundamentada nessas diferenças de gênero, ou seja, na percepção de uma menor responsabilidade masculina pela gravidez e pelo/a futuro/a filho/a. Tal campanha de valorização é mais uma estratégia de prevenção, as quais são distintas para meninos e meninas. Para eles, prevenir significa valorizar a paternidade, mostrando suas responsabilidades frente a essa experiência. Para elas, o trabalho é feito menos no sentido de valorizar a maternidade e mais de mostrar os prejuízos que esta causaria a vida da menina.

Percebemos nesse exemplo uma moral diferenciada por gênero. Os princípios de conduta que regem os comportamentos femininos e masculinos perante a gravidez são diferenciados, seja no que se refere a sua prevenção, seja no que se refere a como lidar com seus possíveis efeitos.

O que é preciso pontuar é que essas diferenças não são naturais, mas socialmente construídas, estando ligadas às construções de gênero presentes na nossa sociedade. Se pensamos no gênero como construções sociais do feminino

3 Um estudo sobre as representações e os arranjos dados por jovens do sexo masculino, oriundos de camadas populares, em relação à gravidez ocorrida na adolescência mostrou que esses jovens interrompiam sua trajetória escolar em prol da profissional, mais por questões materiais do que em função da gravidez em si. Segundo o estudo, está presente nesse universo um imperativo moral que incita o homem à busca pelo trabalho (CABRAL, 2002). Sobre o impacto da gravidez nas trajetórias escolares e profissionais de adolescentes, vide também Heilborn et al (2002). 
e do masculino (SCOTT, 1995), também precisamos pensar na gravidez, na maternidade e na paternidade como construções sociais. Os estudos sobre gênero problematizam argumentos que explicam comportamentos de homens e de mulheres a partir de diferenças naturalizantes. Essas formas de raciocínio, não raro se apoiam em distinções supostamente biológicas para justificar uma série de diferenças sociais e, mais do que isso, desigualdades sociais entre mulheres e homens. Nesse sentido, a suposta maior responsabilidade da mulher por prevenir a gravidez ou por criar os/as filhos, não pode ser vista como uma consequência do fato de mulheres terem útero, ovário, engravidarem, parirem etc. A origem dessa concepção não está em um corpo orgânico, em órgãos sexuais, hormônios ou genes. Trata-se antes de uma construção social, dos significados construídos para a maternidade e a paternidade na nossa sociedade.

Assim, problematizar as construções sociais do feminino e do masculino em um trabalho de educação sexual é uma forma de construir uma equidade de gênero. A ideia de que meninas teriam maior responsabilidade pela gravidez e pelo/a filho/a demonstra uma moral diferenciada e desigual para homens e mulheres. A estratégia escolar de conduzir uma reflexão sobre gravidez centrada no homem pode ser interessante nesse sentido. Não raro, campanhas de prevenção à gravidez são focadas nas mulheres, desconsiderando a responsabilidade masculina no processo. Por outro lado, também encontramos movimentos sociais que reivindicam maiores direitos aos homens no que se refere ao exercício da paternidade (FOLHA DE SÃO PAULO, 2007; TÓFOLI, 2007) ${ }^{4}$. Não obstante tais aspectos progressistas, não é ocioso lembrar o risco de uma reconfiguração conservadora nos moldes daquela encontrada no discurso dos divorcistas quanto a uma concepção tradicional de família e papéis de gênero. Em outras palavras, a iniciativa surge em nome de uma valorização da paternidade. No entanto, a concepção de paternidade aqui pressuposta é heteronormativa. Vale dizer, está concebida para casais heterossexuais. Em momento algum é feita qualquer referência à homoparentalidade.

Ainda nessa perspectiva, uma das perguntas sugeridas pelo jornal e adotada em sala de aula merece ser problematizada: "Como os jovens percebem a mulher que tem relações sexuais com um homem, no primeiro encontro?". Além dessa, outra também esteve presente nas discussões: "É legal a menina conhecer o cara na primeira noite e ir para a cama com ele?".

Antes de abordar o debate em torno da pergunta, cabe observar o fato de ela não ter sido formulada em relação aos homens. Não existia a pergunta

4 O movimento "Pais por Justiça" é formado por homens separados que lutam para ter mais convivência com os filhos. O blog do movimento está disponível em: $<$ http://www.paisporjustica. blogspot.com>. Acesso em: 27/06/09. 
"Como os jovens percebem o homem que tem relações sexuais com uma mulher no primeiro encontro?". Isso parecia não constituir um problema, algo passível de ser questionado. De modo semelhante, em outro debate quando um menino criticou as "mulheres que abrem as pernas para qualquer um", a possibilidade de homens terem um comportamento semelhante não foi nem mesmo cogitada, quando muito, os homens foram criticados por se interessarem por esse "tipo de mulher". Esses debates voltam a exemplificar a presença de morais diferenciadas por gênero, as quais deveriam ser problematizadas. Ter diversos parceiros sexuais é algo condenado para as mulheres, enquanto o mesmo não ocorre em relação aos homens. No máximo, são criticados por se relacionarem com mulheres que adotam esse comportamento. Já as suposições em torno do número de parceiros de uma mulher imprimem-lhe uma identidade, ela é classificada como um "tipo", "tipo" esse socialmente desvalorizado. O mesmo não ocorre em relação aos homens. É como se esse "tipo de homem" não existisse, pois quando esse comportamento é masculino, ele não é nomeado enquanto tal, a ponto de não ser nem mesmo cogitado ou problematizado. Em outras palavras, a moral que determina o número de possíveis parceiros ou o momento em que a primeira relação sexual deve acontecer não são as mesmas para homens e para mulheres.

De acordo com os estudantes, aquele que tem várias parceiras poderia até ser valorizado por isso, seja simplesmente porque isso é visto como "normal", seja porque isso lhe garantiria experiência, afirmando certa masculinidade, sendo assim motivo de admiração - e não de difamação como entre as meninas. São várias as falas que tratam sobre essas diferenças de gênero: "Se um homem transar com todo mundo, todo mundo acha que ele é um machão. Agora se a garota transar com um e com outro, aí já é motivo de boato" (Manfred, 14). Pega mal ter mais de uma paquera: "Ah, ela é uma piranha" (Katlin, 14) (ALTMANN, 2005, p. 128).

Essa questão também foi identificada pela professora de Ciências:

[...] ainda tem discriminação em relação à garota que fica com vários meninos. Eles podem, mas elas não podem. [...] O menino pode pegar várias garotas. Isso aí ainda é considerado como triunfo. Ela não. Se ela ficar com vários garotos ela é cachorra, ela é mal falada, ela é uma garota fácil (ALTMANN, 2005, p. 128).

Vale, portanto, perguntar: como problematizar na escola a ética nas relações de gênero? 
Uma questão que ocupou longo tempo do debate foi sobre se seria ou não adequado um casal ter relações sexuais logo no primeiro dia em que se conhecessem. Os/as estudantes reconheciam que havia casos em que isso acontecia. Uma garota expressou não considerar inadequado esse comportamento, pois se tivesse "rolado uma atração muito grande entre os dois" poderiam dormir juntos já no primeiro encontro.

Essa opinião, no entanto, não era partilhada pela professora. Sua mensagem final em torno desse debate foi de que, antes de uma relação sexual, as pessoas deveriam conversar, se conhecer melhor, o que inclusive facilitaria o uso da camisinha. Também em outros momentos, o uso do preservativo aparecia como dependente de uma negociação que passaria por uma suposta conversa. A necessidade de usá-lo era apresentada dentro de uma relação ideal e não considerando as diversas possibilidades de relação entre duas pessoas. Mais do que prescrever o uso do preservativo, prescrevia-se um tipo de relação: heterossexual e com algumas etapas a serem seguidas. Assim, a importância da camisinha era destacada sempre dentro de um padrão idealizado de relacionamento e não dentro de relacionamentos sexuais de um modo geral, independentemente de quais fossem suas características e configurações. Outras formas de relacionamento eram, direta ou indiretamente, desvalorizadas ou, no mínimo, não consideradas (ALTMANN, 2005).

O debate não era guiado, por exemplo, no sentido de "como um casal, que se conhece em um baile funk e acaba transando na mesma noite, usa camisinha". O curso do debate era de que esse casal não deve transar já na primeira noite, mas esperar, se conhecer melhor e só então ter relações sexuais usando camisinha. Além disso, o casal que aparecia nessas situações era sempre de um garoto e uma garota, ou seja, heterossexual. Não eram construídas situações com relações homossexuais nas quais a camisinha deveria ser usada. Percebese aqui que não há lugar no currículo para a diversidade sexual ou de gênero. Ainda que não explicitado, uma moralidade heterossexual perpassa o trabalho de prevenção. Cabe questionar em que momentos a homossexualidade aparece na escola. Além de situações de preconceitos e de momentos em que se fala sobre DSTs e AIDS, quais são outras formas positivas de se falar sobre homossexualidade na escola? Como desenvolver uma educação sexual que não se restrinja a princípios heteronormativos ${ }^{5}$ ?

Além disso, esse modo de divulgação do uso da camisinha pressupõe racionalização e controle da relação, o qual não era relacionado ao inesperado

5 Sobre a construção de identidades homossexuais na escola, vide Ferrari (2003) e sobre os significados conferidos à homossexualidade a partir de livros paradidáticos relativos à educação sexual vide Furlani (2008). 
ou até mesmo ao descontrole. Essa expectativa de controle subjacente à prática educativa parece pouco condizente com a realidade, conforme têm atestado vários estudos ${ }^{6}$. Na cultura brasileira, a sexualidade masculina hegemônica é frequentemente associada ao descontrole e racionalizar os "impulsos sexuais" acaba sendo visto como não condizente com a virilidade. A fala de um aluno, Manfred, "Na hora a gente não pensa em nada, só pensa em transar, transar, transar!", é exemplar nesse sentido.

\section{Considerações finais}

Baseado no debate supracitado podemos apontar algumas considerações. A atividade proposta de discutir sobre três diferentes experiências de gravidez pode ser interessante, pois ela abriria um espaço de discussão e reflexão ética para com os/as jovens. No entanto, a procedência e a forma de apresentar as situações indicam que não se trata de uma livre e ampla discussão sobre a temática, mas de uma discussão que já vem formatada sob certos parâmetros. Caberia indagar sobre a própria origem de tal iniciativa instituída por decreto. Parece ter um fim pré-determinado, uma "moral da história" qual seja, de apresentar uma situação e um momento ideal em que a maternidade e a paternidade devam ser vividas. Trabalhos de educação sexual não raro adotam atividades conhecidas como "dinâmicas", que geralmente são concluídas com uma moral pré-definida por quem conduz a atividade. Espécie de jogos discursivos que em nome de "abrir o diálogo" colocam em pauta temas, lugares e regimes de fala previamente concebidos e valorados. No caso aqui trabalhado, havia todo um direcionamento do debate para a ideia de que um/a filho/a deve ser desejado e planejado dentro de um relacionamento heterossexual estável e duradouro. Dentro da atividade desenvolvida, há apenas uma única situação em que a gravidez é realmente aceita, qual seja, aquela de um casal com um relacionamento estável e duradouro que deseje e planeje um filho. As outras duas situações apresentam problemas. A primeira situação, apesar do relacionamento ser mais longo, não é ideal, porque carece de planejamento, podendo criar problemas para o casal. A segunda, quando um casal que pouco se conhece se defronta com uma gravidez, era a mais condenada. Nesse caso, além da gravidez, foi ressaltado que teriam corrido riscos de contrair alguma DST ou até mesmo a AIDS. As DSTs e a AIDS são pensadas somente em relações eventuais, quando pesquisas mostram que $\mathrm{o}$

6 Salem (2004); Cabral (2002), entre outros. 
risco de contrair doenças dentro de situações estáveis também é grande. O fato de o uso do preservativo ser menos frequente em relações mais estáveis precisa ser considerado, pois os índices de contaminação por doenças nessas relações não é desprezível. Da mesma forma, o menor uso da camisinha em relações estáveis, se não acompanhado do uso de algum outro método contraceptivo, aumenta as chances de uma gravidez.

Observa-se que a atividade, ao invés de propiciar um múltiplo debate sobre a experiência de gravidez, acaba sendo moralista e prescrevendo um único modelo de gravidez. Mesmo não estando necessariamente inserida dentro do casamento - como já o foi em outros tempos - ela também acaba estando presa a regras morais. Desconsidera-se que as experiências de gravidez, maternidade e paternidade podem ser muitas, incluindo a produção independente, a maternidade e a paternidade por casais homossexuais, a adoção etc.

Uma ética da sexualidade não deveria impedir escolhas individuais por uma moral. A possibilidade de ter um/a filho/a em um contexto diferente daquele tido como ideal deve permanecer aberta. Um trabalho de educação sexual pautado por uma ética poderia criar situações de reflexão sobre o tema, contribuindo para que a gravidez não seja um destino. No entanto, o momento e a circunstância em que ela deva ocorrer na vida de alguém é algo que não deveria ser pré-estabelecido. Pois, nestes casos, recai-se em posições prescritivas ou normativas por mais dissimuladas que estejam.

As reflexões aqui empreendidas visaram colocar a educação sexual sob o prisma da ética como prática da liberdade. Para tanto cabe colocar que tal prática implica a noção de "problematização" tal como Michel Foucault a empregou em seu pensamento. Para o filósofo, problematização não significa a reapresentação de um princípio ou objeto pré-existente, nem a criação pelo discurso de um princípio ou objeto inexistente, mas "o conjunto das práticas discursivas e não discursivas que faz qualquer coisa entrar no jogo do verdadeiro e do falso e a constitui como objeto para o pensamento (seja sob a forma da reflexão moral, do conhecimento científico, da análise política etc.)" (FOUCAULT, 1984).

Se pudermos conceber o papel do professor como não sendo apenas um agente a serviço da moral - aquele que professa e prescreve conteúdos e valores verdadeiros e inquestionáveis de um suposto saber absoluto - talvez possamos concebê-lo como um ator social operando no interior desta rede de valores e condutas. Nessa perspectiva, cada qual atua a partir de seu campo específico, mas produz ligações transversais de um espaço ao outro, de forma a desnaturalizar os campos problemáticos da instituição escolar e possibilitar outras formas de abordagem e tratamento dos dilemas éticos, cumprindo assim uma decisiva função educacional. É neste sentido que a educação e seus agentes podem reencontrar o seu lugar de região sensível de ação ética e política e desengessar a camisa de 
força moralizadora que muitas vezes lhes é imposta. É também aí que os professores podem jogar o seu delicado papel de comutador da realidade social, pois eles se encontram em pontos de cruzamento privilegiados de diferentes dilemas éticos, políticos e epistemológicos. Entre o "certo" e o "errado", entre o "normal" e o "anormal", o "natural" e o "antinatural", o "científico" e o "não científico", enfim, entre o "verdadeiro" e o "falso", os educadores tornam-se notadamente mediadores de operações valorativas em distintos campos de condutas. Portanto, é sobretudo quanto ao seu posicionamento no campo da "ética e da política da verdade" que o educador joga seu decisivo papel enquanto ator social.

\section{REFERÊNCIAS}

ALTMANN, Helena. Pedagogias da sexualidade e do gênero: educação sexual em uma escola. Tese (Doutorado) - Programa de Pós-Graduação em Educação, PUC/ Rio, Rio de Janeiro 2005. Disponível em: <http://www2.dbd.puc-rio.br/pergamum/ biblioteca $/ \mathrm{php} / \mathrm{mostrateses}$.php?open $=1 \&$ arqtese $=0114341$ _05_Indice.html $>$. Acesso em: 25/5/2009.

. Educação sexual em uma escola: da reprodução à prevenção. Cadernos de Pesquisa (Fundação Carlos Chagas), v. 39, p. 175-200, 2009.

AMBIENTE EM REDE. Informativo do Projeto Educação Ambiental e Saúde. A. 2, n. 3, Rio de Janeiro: SME, jul./ago. 2002.

ARCHANJO, Daniela R. A mulher nos debates parlamentares sobre o divórcio (Brasil: décadas de 1950, 1960 e 1970). In: SEMINÁRIO INTERNACIONAL FAZENDO GÊNERO, 7: Gênero e Preconceitos, Florianópolis, 2006.

. Um debate sem embate: a discussão sobre o divórcio no Congresso Nacional (Brasil, 1951-1977). Tese (Doutorado em História) - UFPR, Curitiba 2008.

CÉSAR, Maria R. de A. Gênero e sexualidade na educação: notas para uma reflexão epistemológica. In: ENDIPE - TRAJETÓRIAS E PROCESSOS DE ENSINAR E APRENDER: LUGARES, MEMÓRIAS E CULTURAS, 14., 2008, Porto Alegre. Anais... Porto Alegre: PUC, 27 a 30 abr. 2008.

CABRAL, Cristiane da S. Novos pais, jovens pais: vicissitudes da paternidade entre jovens de uma comunidade favelada do município do Rio de Janeiro. Dissertação (Mestrado em Saúde Coletiva) - Instituto de Medicina Social, Universidade Estadual do Rio de Janeiro, Rio de Janeiro, 2002. 
CHAUÍ, Marilena. Convite à filosofia. São Paulo: Editora Ática, 1995.

LA TAILLE, Yves de. Ética e sexualidade: pauta para reflexão. Entretextos/Entresexos, Campinas, Unicamp, n. 2, p. 69-80, out. 1998.

FERRARI, Anderson. "Esses alunos desumanos": a construção das identidades homossexuais na escola. Educação e Realidade, Porto Alegre, n. 28, v. 1, p. 87-111, jan./jul. 2003.

FOUCAULT, Michel. A história da sexualidade 1. A vontade de saber. 12. ed. Tradução de: M. T. da C. Albuquerque e J. A. G. Albuquerque. Rio de Janeiro: Graal, 1997.

. A Ética do cuidado de si como prática da liberdade. In: Dits et Écrits, Paris: Quatro, Gallimard, 1994. V. V.

. O cuidado com a verdade. In: ESCOBAR, Carlos H. (Org.). $O$ dossier: últimas entrevistas. Tradução de: Maria G. Silva e Ana M. Lima. Rio de Janeiro: Taurus, 1984.

FURLANI, Jimena. Mulheres só fazem amor com homens? A educação sexual e os relacionamentos entre pessoas do mesmo sexo. Pro-posições, v. 19, p. 111-131, 2008.

HEILBORN, Maria L.; SALEM, Tânia; ROHDEN, Fabíola; BRANDÃO, Elaine; KNAUTH, Daniela, VÍCTORIA, Ceres; AQUINO, Estela; McCALLUM, Cecília; BOZON, Michel. Aproximações sócio-antropológicas sobre a gravidez na adolescência. Horizontes Antropológicos, Porto Alegre, a. 8, n.17, p. 13-44, jun. 2002.

HEILBORN, Maria L. O mal-estar brasileiro não é responsabilidade das meninas pobres. Disponível em: <http://www.clam.org.br/publique/cgi/cgilua.exe/sys/start.ht m?UserActiveTemplate $=\% 5$ FBR \&infoid $=2488 \&$ sid $=4>$. Acesso em: 17/4/2007.

PAIS protestam por mais tempo com seus filhos. Folha de São Paulo, Caderno Cotidiano, p. C6, 13/8/2007.

RANCIÈRE, Jacques. O Dissenso. In: NOVAES, Adauto (Org.). A Crise da Razão. São Paulo: Editora Schuartz, 1996.

RIO DE JANEIRO (Município). Decreto n. ${ }^{\circ} 21649$ de 27 de junho de 2002, Institui a Semana de Valorização da Paternidade, na segunda semana de agosto. Diário Oficial [do Município do] Rio de Janeiro, de 28/6/2002, p. 3. Disponível em: <http://www. saude.rio.rj.gov.br/media/Dsms21649.doc>. Acesso em: 25/5/09.

SCOTT, Joan. Gênero: uma categoria útil de análise histórica. Educação e Realidade, Porto Alegre, v. 20, n. 2, p. 71-99, jul./dez. 1995. 
TÓFOLI, Daniela. Solteiro adota para realizar sonho de ser pai. Folha de São Paulo, Caderno Cotidiano, p. C3, 12/8/2007.

Texto recebido em 4 de junho de 2009. Texto aprovado em 10 de julho de 2009. 